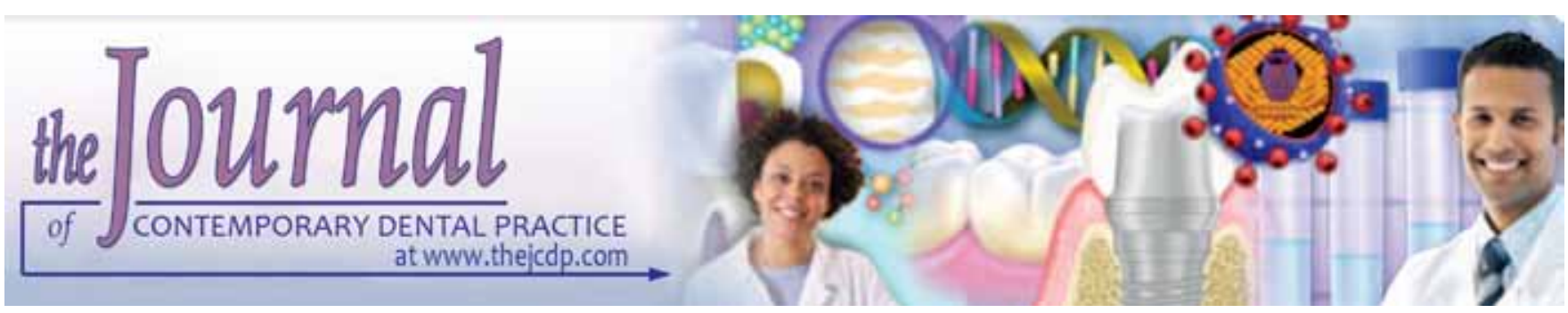

\title{
Evaluation of Apically Extruded Debris and Irrigant Produced by Different Nickel-Titanium Instrument Systems in Primary Teeth
}

${ }^{1}$ Ebru Kucukyilmaz, ${ }^{2}$ Selcuk Savas, ${ }^{3}$ Gokhan Saygili, ${ }^{4}$ Banu Uysal

\begin{abstract}
Aim: The purpose of this study was to determine the amount of extruded debris and irrigant associated with different single-file systems and one multiple-file system.
\end{abstract}

Materials and methods: Forty-five newly extracted single rooted primary canine teeth were used in this study. The root canals were instrumented using the reciprocating single-file system, the single-file rotary system and the multiple-file rotary system. A $10^{-6}$ precision micro-balance was used to calculate the amount of extruded debris and irrigant. The incubation period was set as 15 days at $37^{\circ} \mathrm{C}$ to obtain dry debris. The preparation time for instrumentation was also recorded. The data were statistically analyzed by Manova and Bonferroni adjustment.

Results: Considering the apically extruded debris, while there was statistically significant difference between Reciproc and OneShape groups $(p<0.05)$, no statistically significant difference was found among the other groups $(p>0.05)$. In terms of irrigation solution, although significant difference was obtained between the Reciproc and other two groups $(p<0.05)$, no statistically significant difference was obtained between the two rotary instruments $(p>0.05)$. Instrumentation was significantly faster using Reciproc than with all other instrument $(p<0.05)$.

Conclusion: All systems caused apical debris and irrigant extrusion. Full-sequences rotary instrumentation systems may be preferable for preparation primary teeth.

Clinical significance: This is the first study carrying out to compare both apical debris and irrigation solution extrusion with reciprocal and rotary single-file systems with other preparation systems in primary teeth.

\footnotetext{
${ }^{1,2}$ Department of Pediatric Dentistry, Faculty of Dentistry, Izmir Katip Celebi University, Izmir, Turkey

3,4 Department of Endodontics, Faculty of Dentistry, Izmir Katip Celebi University, Izmir, Turkey

Corresponding Author: Ebru Kucukyilmaz, Assistant Professor, Department of Pediatric Dentistry, Faculty of Dentistry Izmir Katip Celebi University, Cigli, Izmir, Turkey, Phone: +902323524040, e-mail: ebrukucukyilmaz@hotmail.com
}

Keywords: Instrumentation, Primary teeth, Root canal irrigants, Root canal preparation.

How to cite this article: Kucukyilmaz E, Savas S, Saygili G, Uysal B. Evaluation of Apically Extruded Debris and Irrigant Produced by Different Nickel-Titanium Instrument Systems in Primary Teeth. J Contemp Dent Pract 2015;16(11):864-868.

Source of support: Nil

Conflict of interest: None

\section{INTRODUCTION}

Maintaining the primary dentition in the dental arch is important for normal jawbone and muscle development, good pronunciation, and eruption of the permanent teeth at the correct position. Altered function and phonation, development of aberrant habits, ectopic eruption, space loss of permanent teeth, and disturbance in the eruption sequence may be caused by early loss of primary teeth. ${ }^{1-3}$

One of the main causes of early loss of primary teeth is periapical infection. ${ }^{4}$ Root canal therapy of primary teeth is routinely practiced and effective in treating of irreversible inflammation or infected pulpal tissue. ${ }^{5}$ To achieve healing with endodontic treatment, it is necessary that all procedures are carried out successfully with the aim of maintaining or healing the periradicular tissues, saving the primary tooth until eruption of its permanent successor. $^{6}$

Chemomechanical preparation of root canals is an indispensable step of endodontic treatment. However, during preparation, necrotic debris, pulp remnants, microorganisms, dentin chips, and irrigants may be extruded into the apical region. ${ }^{6,7}$ These may lead to inflammation, flare-ups, and delays in healing or possible damage to the permanent tooth germs. ${ }^{8}$ Numerous studies have evaluated the extrusion of intracanal materials through the periapical region. ${ }^{6,7,9}$ A common finding is 
that all instrumentation systems produce apical extrusion. However, the type of instrumentation system affects the amount of apical extrusion. 6,7,9

Various instruments are used for root canal treatment in primary teeth, such as manual instrumentation systems, multi-file nickel-titanium (NiTi) rotary systems, and single-file NiTi rotary systems. ${ }^{10,11}$ Evaluations of studies of the use of rotary NiTi files in primary teeth revealed the following advantages of these systems: preservation of the original anatomy of root canals, reduced procedural errors, time savings, and a more predictable uniform paste filling because of the funnel-shaped canal preparation. ${ }^{12,13}$

OneShape (Micro-Mega, Cedex, France) and Reciproc (VDW, Munich, Germany) single-file NiTi systems that prepare the entire root canals with only one instrument have recently been introduced. Reciproc files are made of M-wire NiTi, which offers increased flexibility. The reciprocating movement of this instrument also reduces the risk of cyclic fatigue. ${ }^{14,15}$ In contrast; OneShape files have a traditional continuous rotation movement. They have a triangle cutting edge and two cutting edges in the apical and coronal part, respectively, and a cross-section that progressively changes from three to two cutting edges between the apical and coronal parts. This design offers an optimal cutting action. ${ }^{14}$

To the best our knowledge, no studies have been carried out to compare both apical debris and irrigation solution extrusion with reciprocal and rotary single-file systems with other preparation systems in primary teeth. The purpose of this study was to determine the preparation time and the amount of apically extruded debris and irrigant using the two new single-file systems, OneShape and Reciproc, compared with the rotary full-sequence ProTaper (Dentsply Maillefer, Ballaigues, Switzerland) system.

\section{MATERIALS AND METHODS}

The present study was approved by the Research Ethics Committee of the Izmir Katip Celebi University, under report no. 2014/73. In this study, a total of 45 freshly extracted human primary canine teeth with closed apex, without resorption and straight root canals $\left(<5^{\circ}\right.$ according to the Schneider method) were selected. ${ }^{16}$ The teeth were cleaned of external debris and soft-tissue remnants and were stored in a saline solution. All the teeth were analyzed with a digital radiograph to ensure that they had single canals.

To standardize the length of the root of all samples, the crowns of the teeth were removed with a high-speed hand piece bur. The working length of each tooth was determined by inserting a size 15 K-file (Dentsply,
Maillefer, Ballaigues, Switzerland) in the canal until the tip of the file was just visible at the apical foramen and then it set as $1 \mathrm{~mm}$ less than the canal length. A total of 45 teeth were classified into three groups:

Group 1: ProTaper instruments were used according to the manufacturer's instructions as follows: S1, S2, F1, F2 $(\mathrm{n}=15)$.

Group 2: An R25 Reciproc file having a size 25 at the tip and a taper of 0.08 over the first $3 \mathrm{~mm}$ was used according to the manufacturer's instructions with reciprocal action $(\mathrm{n}=15)$.

Group 3: A OneShape file having a size 25 at the tip and a taper of 0.06 was used according to the manufacturer's instructions with rotational motion $(n=15)$.

In this study, experimental model described by Myers and Montgomery ${ }^{17}$ was used. Before starting the experiment, the initial weights of empty Eppendorf tubes were measured with a $10^{-6}$ precision electronic balance (Sartorius Cubis, Gottingen, Germany). One hundred sequential weights were obtained for each tube using the Sarto Connect Version 3.5 program, which is specially designed to record one measurement per second. The mean value was calculated for each tube and recorded as its precise weight. The Eppendorf tubes were fitted into glass vials used to hold the tubes during the instrumentation to ensure that there was no contact with the tubes.

To avoid variation and eliminate biases, the cleaning, shaping, and irrigation of all the samples were completed by the same trained operator. In each sample, a total of $4 \mathrm{ml}$ of bidistilled water was used as the irrigation solution between the files (group 1) and between the pecking sequences (groups 2 and 3). A 25 gauge open ended irrigation needle was placed in the canal without resistance but not deeper than the predetermined working length minus $1 \mathrm{~mm}$.

After the instrumentation, the debris adhered to the root surface was collected by washing the root with $1 \mathrm{ml}$ of bidistilled water in the tube. Each Eppendorf tube with debris and irrigant was weighed to determine the amount of total intracanal material extruded to the periapical area and then stored in an incubator at $37^{\circ} \mathrm{C}$ for 15 days to evaporate moisture before weighing the dry debris. After that period, a blinded second examiner calculated the weight of the debris with the same analytical balance. For each tube, one hundred consecutive weights were achieved. The weight of the empty tube was subtracted from the weight of the tube containing the debris, and the dry weight was recorded for each tube. The total preparation time (active instrumentation, instrument changes within the sequence, cleaning of the flutes of the instruments, and irrigation) was recorded. 


\section{STATISTICAL ANALYSIS}

Before beginning the study, a power analysis was performed with G*Power 3.0.10 (Franz Faul, ChristianAlbrechts-Universität, Kiel, Germany) to estimate the sample size. A power analysis done based on the effects obtained from a prior pilot study with five subjects in each group with a total of 15 subjects indicated that a multivariate analysis of variance (MANOVA) design with 1 factor with 3 levels and three response variables; extruded debris, irrigant, and preparation time, and with 15 subjects in each group for a total of 45 subjects could achieve $88.6 \%$ statistical power to test the factor 'different instruments' with three levels if a Wilks' Lambda approximate $\mathrm{F}$ test is used with a $5 \%$ significance level.

The amount of extruded irrigant and debris and the preparation times were analyzed using the statistical package for the social science (SPSS 20.0) computer program (SPSS, Chicago, IL). The dependent variable across the groups was examined in terms of the existence normality assumption by performing a Shapiro-Wilk test. Levene's test was used to evaluate constant homogeneous variances. The test indicated that the variables across the groups met the underlying assumption of the parametric tests fairly well. Accordingly, the data were analyzed statistically using MANOVA and post hoc Bonferroni adjusted at a significance level of $\mathrm{p}<0.05$.

\section{RESULTS}

There was a statistically significant difference in the apical extrusion of debris between the Reciproc and OneShape groups $(\mathrm{p}<0.05)$, no statistically significant difference was found among the other groups $(p<0.05)$. While the lowest amount of extruded debris was observed with the Reciproc system $(0.000378 \pm 0.000271 \mathrm{gr})$, the highest amount was observed with the OneShape system $(0.000558 \pm 0.000171 \mathrm{gr})$. Table 1 presents the mean values and standard deviations for all the groups.

Regarding the apical extrusion irrigation solution, although there was no statistically significant difference between the OneShape and ProTaper groups ( $p>0.05)$, significant differences were found between the Reciproc and other groups $(\mathrm{p}<0.05)$. The highest amount of extruded irrigant was observed with Reciproc (1.121666

Table 1: Amount of apically extruded debris (gram) after the use of the different instruments

\begin{tabular}{llll}
\hline $\begin{array}{l}\text { Extruded } \\
\text { debris }\end{array}$ & Mean $\pm S D$ & Minimum & Maximum \\
\hline ProTaper & $0.000407^{\mathrm{a}, \mathrm{b}} \pm 0.000116$ & 0.000165 & 0.000597 \\
Reciproc & $0.000378^{\mathrm{a}} \pm 0.000271$ & 0.000183 & 0.001305 \\
OneShape & $0.000558^{\mathrm{b}} \pm 0.000171$ & 0.000316 & 0.000950 \\
\hline
\end{tabular}

The letters sign statistically different groups $(p<0.05)$
Table 2: Amount of apically extruded irrigant (milliliter) after the use of the different instruments

\begin{tabular}{llll}
\hline $\begin{array}{l}\text { Extruded } \\
\text { irrigant }\end{array}$ & Mean $\pm S D$ & Minimum & Maximum \\
\hline ProTaper & $0.620893^{\mathrm{a}} \pm 0.309965$ & 0.277000 & 1.258418 \\
Reciproc & $1.121666^{\mathrm{b}} \pm 0.308653$ & 0.296991 & 1.603569 \\
OneShape & $0.823023^{\mathrm{a}} \pm 0.345030$ & 0.270826 & 1.439791 \\
\hline
\end{tabular}

The letters sign statistically different groups $(p<0.05)$

Table 3: Preparation time with the different instruments

\begin{tabular}{llll}
\hline Preparation time & Mean $\pm S D$ & Minimum & Maximum \\
\hline ProTaper & $98.33^{\mathrm{a}} \pm 15.90$ & 80 & 126 \\
Reciproc & $52.00^{\mathrm{b}} \pm 14.80$ & 38 & 86 \\
OneShape & $66.40^{\mathrm{c}} \pm 15.80$ & 45 & 107 \\
\hline
\end{tabular}

The letters sign statistically different groups $(p<0.05)$

$\pm 0.308653 \mathrm{ml})$ and the lowest with the ProTaper system $(0.620893 \pm 0.309965 \mathrm{ml})$. Table 2 presents the mean values and standard deviations for all the groups.

Considering the preparation time, there was a statistically significant difference between all the groups $(\mathrm{p}<0.05)$. The minimum preparation time was recorded with the Reciproc files $(52.00 \pm 14.80$ s). Table 3 presents the mean values and standard deviations for each group.

\section{DISCUSSION}

As shown in previous studies that evaluated the use of rotary NiTi files in primary teeth, the results varied according to the systems compared. ${ }^{12,13,18-21}$ According to these studies, the main advantage of these systems appears to be time savings. ${ }^{18-21}$ To our knowledge, no studies have been carried out to investigate apical extrusion of rotary systems in primary teeth. Therefore, the main purpose of the current study was to compare the apical extrusion of debris and irrigant during root canal preparation by different NiTi systems.

Until today, intracanal materials extrusion has been investigated in many studies, $6,7,9,14$ because of possible complications, such as delay of periapical healing, inflammation and postoperative pain. For successful root canal treatment, it is important to minimize the amount of apically extruded debris and irrigants. ${ }^{8,22}$ While there were different techniques for measuring the apically extruded debris and irrigant, ${ }^{17,23}$ the generally accepted method of Myers and Montgomery were used in the current study to collect the apically extruded debris. ${ }^{17}$

The amount of apical extrusion has been effect by many factors. The instrumentation method, the size and length of the canal, the instrument type and size, the preparation endpoint, and the type and the amount of irrigant used are also the main factors. $6,7,9,14,23,25$ In the present study, standard conditions were created for each instrumentation type. The teeth were radiographed, and 
only single-rooted teeth with straight canals were used in this study. For this purpose, the crowns of the teeth were removed with a high-speed hand piece bur, and the length of the root of all the samples was standardized. It has been reported that significantly more debris was forced apically when the instrumentation was performed at the apical foramen than it was $1 \mathrm{~mm}$ short. ${ }^{25}$ Therefore, the working length was determined $1 \mathrm{~mm}$ shorter than the root length in the current study.

In the current study, the type and the quantity of irrigants used were the same. To avoid any possible weight increase due to crystallization of sodium hypochlorite, bidistilled water was used as an irrigation solution and the amount of the solution was kept constant for all the groups.

In the literature, many researchers examined only the amount of apically extruded dry debris. ${ }^{6,7,14,20,24}$ During chemomechanical preparation of root canals, irrigation solutions can accidentally be extruded into the periapical area, as well as intracanal debris. Therefore, the present study focuses on the extrusion of intracanal irrigants, in addition to solid debris. In clinical conditions, both debris and irrigant are responsible for postoperative flare-ups.

The present study revealed that all instrumentation systems cause apical extrusion of debris and irrigants. According to the results of the present study, the greatest amount of irrigation solution extrusion among the groups was observed with Reciproc. This result is likely due to the reciprocating movement of the instrumentation system. Regarding the debris extrusion, Reciproc showed less debris extrusion compared with other systems. This observation is in agreement with previous findings that reciprocating systems are associated with less debris extrusion compared with rotary systems. ${ }^{25-27}$ However, some researchers suggested that rotary movement cause less debris extrusion than reciprocation or there are no differences between two systems. ${ }^{14,20,28-31}$ The obtained differences between the studies may be caused by the different study protocols, different preparation techniques and cross-sectional designs of the instruments, the dissimilar tapers, and the variations of the working length of the selected teeth used in the studies. The Reciproc system has an identical S-shaped cross-sectional design with sharp cutting edges, ${ }^{14}$ whereas OneShape has a changing triangular cross-section ${ }^{14}$ and ProTaper has a triangular or modified triangular cross-section. ${ }^{27}$ Reciproc files use a reciprocating motion, and OneShape and ProTaper employ a rotational movement. Additionally, Reciproc is produced with M-Wire nickel-titanium material that improves the file flexibility while still retaining cutting efficiency. This technology allows to the Reciproc system prepare highly curved canals without excessive shaping. This may be another factor leading the less debris extrusion. The analysis of the data obtained from the current study showed that the differences in the cross-sectional designs and kinematics of the selected systems affect the amount of apically extruded debris. Further studies using standardized conditions should be designed to identify the exact reason.

In contrast the Reciproc and OneShape systems, the ProTaper system requires four instruments to prepare the root canal to a size of 25 . Thus, the single-file systems used in the study were faster than the ProTaper system, and the difference was statistically significant. This finding is consistent with previous studies, which found that the use of single-file systems reduced the working time compared to a multi-file rotary system in permanent teeth. ${ }^{14,20}$

Rotary instrument in primary root canal treatments gain popularity in recent years. Using NiTi rotary files for root canal preparation in primary teeth was cost-effective and faster, and resulted in consistently uniform and predictable fillings. ${ }^{32}$ However, the major disadvantages of the using greater taper instruments for primary root canal preparation is that they may lead to lateral perforation on the inner root surface, especially in curved primary molar roots. ${ }^{33}$ Clinicians should be awareness of the possible risks of the use of these instrument in primary teeth.

\section{CONCLUSION}

- All instrumentation systems produce apical extrusion of debris and irrigation solution.

- Considering the clinical importance of the amount of apically extruded debris and irrigant, all the systems used for root canal preparation should be evaluated in further studies.

\section{REFERENCES}

1. Takushige T, Cruz EV, Asgor Moral A, Hoshino E. Endodontic treatment of primary teeth using a combination of antibacterial drugs. Int Endod J 2004 Jan;37(Suppl):132-138.

2. Pinky C, Shashibhushan KK, Subbareddy VV. Endodontic treatment of necrosed primary teeth using two different combinations of antibacterial drugs: an in vivo study. J Ind Soc Pedod Prev Dent 2011 Apr-Jun;29(2):121-127.

3. Bodur H, Odabas M, Tulunoglu O, Tinaz AC. Accuracy of two different apex locaters in primary teeth with and without root resorption. Clin Oral İnvest 2008 Jun;12(2):137-141.

4. Nunes AC, Nojha MC. Hydroxyl and calcium ions diffusion from endodontic materials through roots of primary teeth-in vitro study. J Appl Oral Sci 2005 Jun;13(2):187-192.

5. Fuks AB. Pulp therapy for the primary and young permanent dentitions. Dent Clin North Am 2000 Jan;44(3):571-596.

6. Albrecht LJ, Baumgartner JC, Marshall JG. Evaluation of apical debris removal using various sizes and tapers of ProFile GT files. J Endod 2004 Jun;30(6):425-428.

7. Adl A, Sahebi S, Moazami F, Niknam M. Comparison of apical debris extrusion using a conventional and two rotary techniques. Iran Endod J 2009;4:135-138. 
8. Seltzer S, Naidorf IJ. Flare-ups in Endodontics I. Etiological factors. J Endod 1985 Jun;11(11):472-478

9. Ferraz CC, Gomes NV, Gomes BP, Zaia AA, Teixeira FB, Souza-Filho FJ. Apical extrusion of debris and irrigants using two hand and three engine-driven instrumentation techniques. Int Endod J 2001;34:354-358.

10. Silva LA, Leonardo MR, Nelson-Filho P, Tanomaru JM. Comparison of rotary and Manuel instrumentation techniques on cleaning capacity and instrumentation time in deciduous molars. J Dent Child 2004 Jul;34(5):45-47.

11. Azar MR, Mokhtare M. Rotary Mtwo system versus manual K-file instruments: efficacy in preparing primary and permanent molar root canals. Ind J Dent Res 2011 MarApr:22(2):363.

12. Madan N, Rathnam A, Shigli AL, Indushekar KR. K-file vs ProFiles in cleaning capacity and instrumentation time in primary molar root canals: an in vitro study. J Ind Soc Pedod Prev Dent 2011 Jan-Mar;29(1):2-6.

13. Nagaratna PJ, Shashikiran ND, Subbareddy VV. In vitro comparison of NiTi rotary instruments and stainless steel hand instrument in root canal preparations of primary and permanent molar. J Ind Soc Pedod Prev Dent 2006 Dec;24(4);186-191.

14. Bürklein S, Benten S, Schäfer E. Quantitative evaluation of apically extruded debris with different single file systems: Reciproc, F360, and OneShape versus Mtwo. Int Endod J 2014 May;47(5):405-409.

15. Liu R, Hou BX, Wesselink PR, Wu MK, Shemesh H. The incidence of root micro cracks caused by 3 different singlefile systems versus the ProTaper system. J Endod 2013 Aug;39(8):1054-1056.

16. Schneider SW. A comparison of canal preparations in straight and curved root canals. Oral Surg 1971 Aug;32(2):271-275.

17. Myers GL, Montgomery S. A comparison of weights of debris extruded apically by conventional filling and Canal Master techniques. J Endod 1991 Jun;17(6):275-279.

18. Canoglu H, Tekcicek MU, Cehreli CH. Comparison of conventional, rotary, and ultrasonic preparation, different final irrigation regimens, and 2 sealers in primary molar root canal therapy. Pediatr Dent 2006 Nov-Dec;28(6):518-523.

19. Da Costa CC, Kunert GG, Da Costa Filho LC, Kunert IR. Endodontic in primary molars using ultrasonic instrumentation. J Dent Child 2008 Jan-Apr;75(1):20-23.

20. Bürklein S, Schäfer E. Apically extruded debris with reciprocating single-file and full-sequence rotary instrumentation systems. J Endod 2012 Jun;38(6):850-852.
21. Kielbassa AM, Muller U, Munz I, Monting JS. Clinical evaluation of the measuring accuracy of the ROOT ZX in primary teeth. Oral Surg Oral Med Oral Pathol Oral Radiol Endod 2003;95:94-100.

22. Siqueira JF Jr. Microbial causes of endodontic flare-ups. Int Endod J 2003;36:453-463.

23. Fairbourn DR, McWalter GM, Montgomery S. The effect of four preparation techniques on the amount of apically extruded debris. J Endod 1987 Mar;13(3):102-108.

24. Beeson T, Hartwell G, Thornton J, Gunsolley J. Comparison of debris extruded apically in straight canals: conventional filling versus Profile 04 Taper series 29. J Endod 1998 Jan;24(1):18-22.

25. Kocak S, Kocak MM, Saglam BC, Türker SA, Sagsen B, Er O. Apical extrusion of debris using self-adjusting file, reciprocating single file and 2 rotary instrumentation systems. J Endod 2013 Oct;39(10):1278-1280.

26. Üstün Y, Çanakçi BC, Dinçer AN, Er O, Düzgün S. Evaluation of apically extruded debris associated with several NiTi systems. Int Endod J 2015 Jul;48(7):701-704.

27. Lu Y, Chen M, Qiao F, Wu L. Comparison of apical and coronal extrusions using reciprocating and rotary instrumentation systems. BMC Oral Health 2015 Aug; 15:92.

28. Kirchhoff AL, Fariniuk LF, Mello I. Apical extrusion of debris in flat-oval root canals after using different instrumentation systems. J Endod 2015 Feb;41(2):237-241.

29. Özsu D, Karatas E, Arslan H, Topcu MC. Quantitative evaluation of apically extruded debris during root canal instrumentation with ProTaper Universal, ProTaper Next, WaveOne, and self-adjusting file systems. Eur J Dent 2014 Oct-Dec;8(4):504-508.

30. Surakanti JR, Venkata RC, Vemisetty HK, Dandolu RK, Jaya NK, Thota S. Comparative evaluation of apically extruded debris during root canal preparation using ProTaper ${ }^{\mathrm{TM}}$, Hyflex $^{\mathrm{TM}}$ and Waveone ${ }^{\mathrm{TM}}$ rotary systems. J Conserv Dent 2014 Mar;17(2):129-132.

31. Topçuoğlu HS, Üstün Y, Akpek F, Aktı A, Topçuoğlu G. Effect of coronal flaring on apical extrusion of debris during root canal instrumentation using single-file systems. Int Endod J 2015 Aug 18. DOI: 10.1111/iej.12520. [Epub ahead of print].

32. Barr ES, Kleier DJ, Barr NV. Use of nickel-titanium rotary files for root canal preparation in primary teeth. Pediatr Dent 1999 Nov-Dec;21(7):453-454.

33. Musale PK, Mujawar SA. Evaluation of the efficacy of rotary vs hand files in root canal preparation of primary teeth in vitro using CBCT. Eur Arch Paediatr Dent 2014 Apr;15(2): 113-120. 